\title{
Lusioersily
}

\section{"Constipation is a Simple Thing": Exploring Healthcare Professionals' Perspectives of Managing Constipation within Specialist Palliative Care: A Qualitative Study}

Mcllfatrick, S. J., Muldrew, D., Carduff, E., Clarke, M., Coast, J., Finucane, A., Graham-Wisener, L., Larkin, P. J., MacArtney, J., McCorry, N., Slater, P. F., Watson, M., Wright, E., \& Hasson, F. (2019). "Constipation is a Simple Thing": Exploring Healthcare Professionals' Perspectives of Managing Constipation within Specialist Palliative Care: A Qualitative Study. Palliative Medicine, (EAPC Abstracts). https://doi.org/10.1177/0269216319844405

Link to publication record in Ulster University Research Portal

Published in:

Palliative Medicine

Publication Status:

Published (in print/issue): 21/05/2019

DOI:

https://doi.org/10.1177/0269216319844405

\section{General rights}

Copyright for the publications made accessible via Ulster University's Research Portal is retained by the author(s) and / or other copyright owners and it is a condition of accessing these publications that users recognise and abide by the legal requirements associated with these rights.

\section{Take down policy}

The Research Portal is Ulster University's institutional repository that provides access to Ulster's research outputs. Every effort has been made to ensure that content in the Research Portal does not infringe any person's rights, or applicable UK laws. If you discover content in the Research Portal that you believe breaches copyright or violates any law, please contact pure-support@ulster.ac.uk. 

Professionals' Perspectives of Managing Constipation within Specialist Palliative Care: A Qualitative Study

\author{
Mcllfatrick, S. ${ }^{1}(\mathrm{PI})$, Muldrew, D.H.L. ${ }^{1}$, Carduff, E. ${ }^{2}$, Clarke, $\mathrm{M}^{3}$., Coast, J. ${ }^{4}$, Finucane, A. ${ }^{2}$, Graham-Wisener, L. ${ }^{3}$, Hasson, F. ${ }^{1}$, \\ Larkin, P. ${ }^{5}$, MacArtney, J. ${ }^{2}$, McCorry, N. ${ }^{3}$, Slater, P. ${ }^{1}$, Watson, M. ${ }^{6}$, \& Wright, E. ${ }^{7}$ \\ ${ }^{1}$ Ulster University, UK ${ }^{2}$ Marie Curie Hospice, UK ${ }^{3}$ Queens University Belfast, UK, ${ }^{4}$ University of Bristol, UK ${ }^{5}$ University of Lausanne, Switzerland, ${ }^{6}$ Hospice UK, London, \\ UK ${ }^{9}$ R\&D PPI representative, Belfast, UK \\ This work was supported by Marie Curie [grant number ref. MCCC-RP-16-20993]
}

\section{Introduction}

Constipation is a major problem, and significant concern, for many patients who are receiving specialist palliative care (SPC). Whilst clinical guidelines have been developed, there is a dearth of evidence regarding healthcare professionals (HCPs) experiences of constipation management within such settings.

Aim: To explore healthcare professionals (HCPs) perspectives of managing constipation within SPC settings

\author{
Definitions \\ 1. Constipation is a condition identified by unsatisfactory \\ defecation due to infrequent stools, difficulty passing stools, or \\ the sensation of incomplete emptying (1). \\ 2. Palliative care aims to improve the quality of life of patients \\ and their families through the prevention and relief of \\ distressing physical, psychological, and social problems (2)
}

\section{Methods}

Focus groups

Sample: $27 \mathrm{HCPs}$

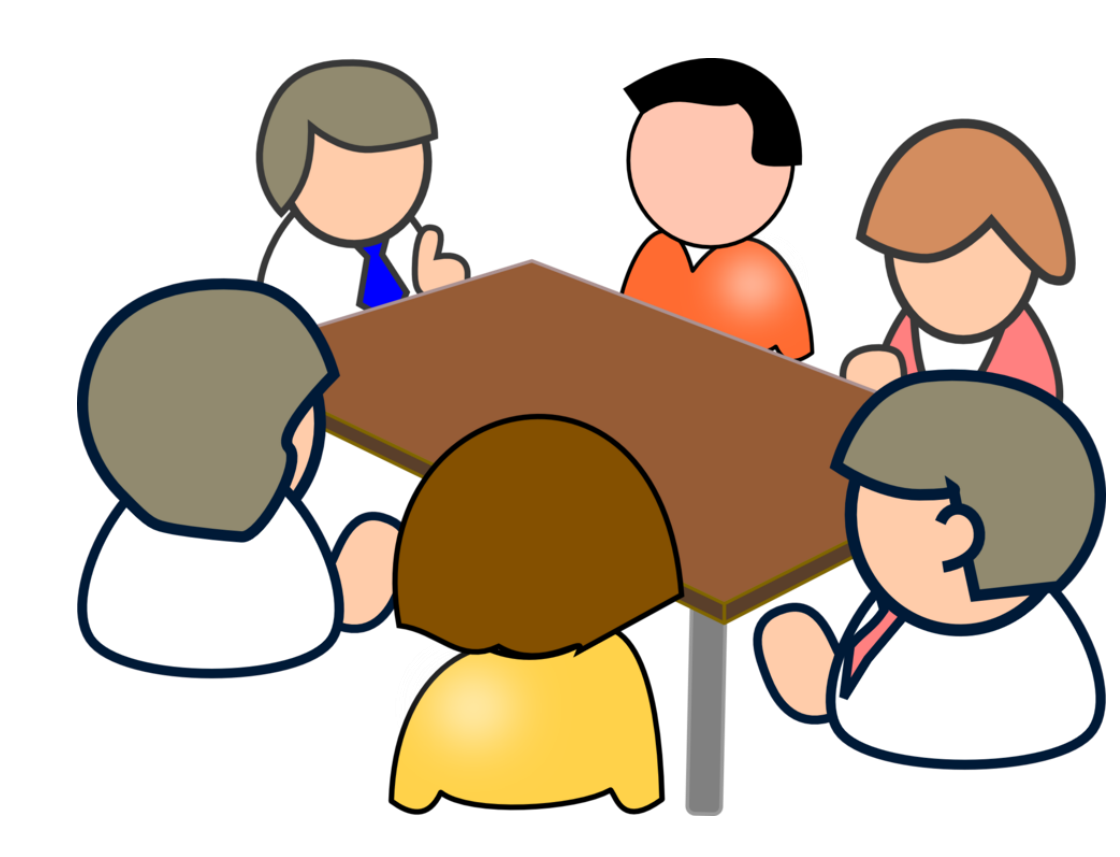

- Doctors $n=7$

- Nurses $n=14$

- Pharmacists $n=1$

- Other $n=5$

Setting: 3 specialist palliative care units

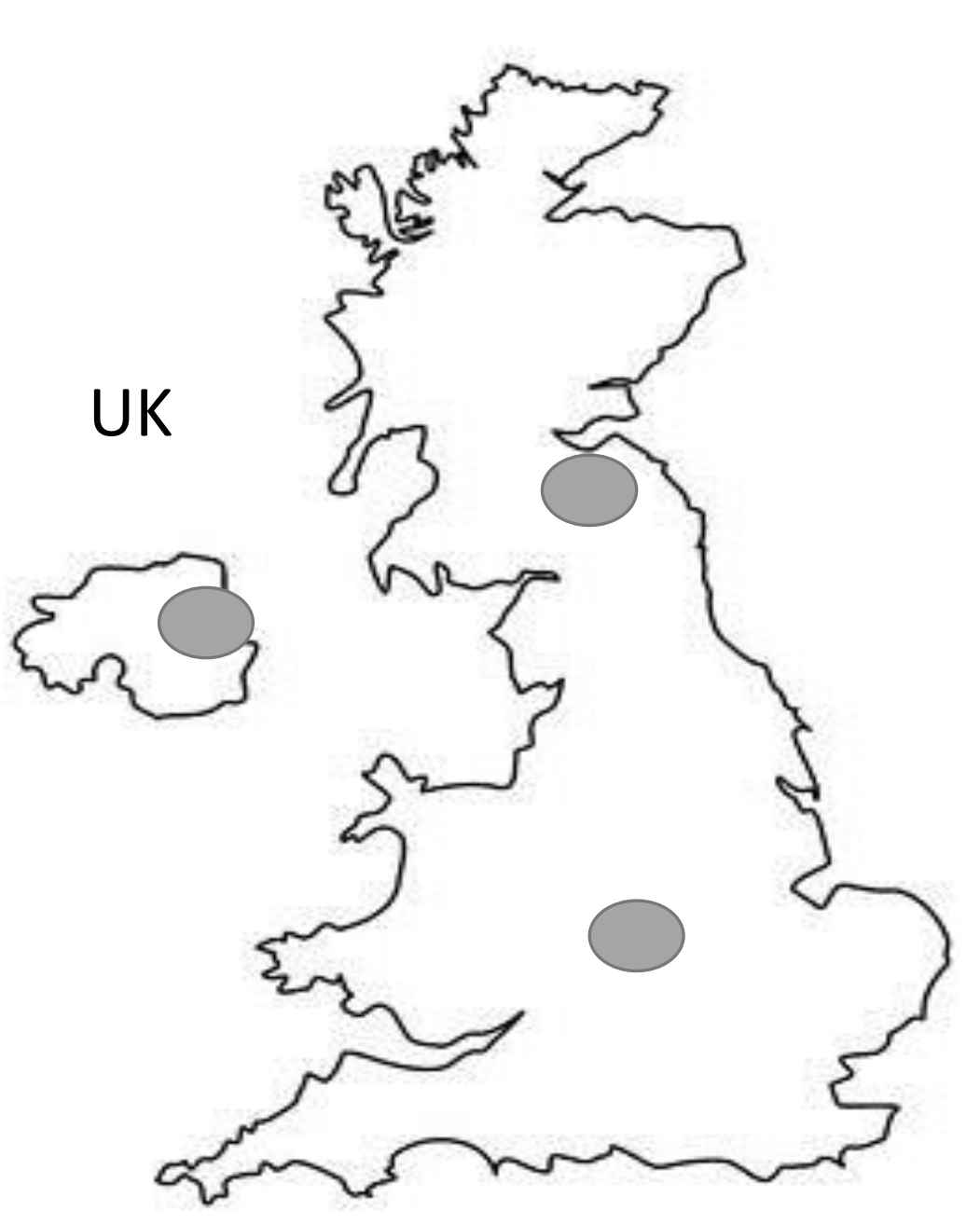

Dates: Nov. 2016 - Jan. 2017

Topics: Knowledge clinical practices and barriers/ facilitators surrounding constipation assessment/ management in SPC units.

Analysis: Braun and Clark's (2006) framework for thematic analysis.

Approval from the Office for Research Ethics Committees Northern Ireland (ORECNI)

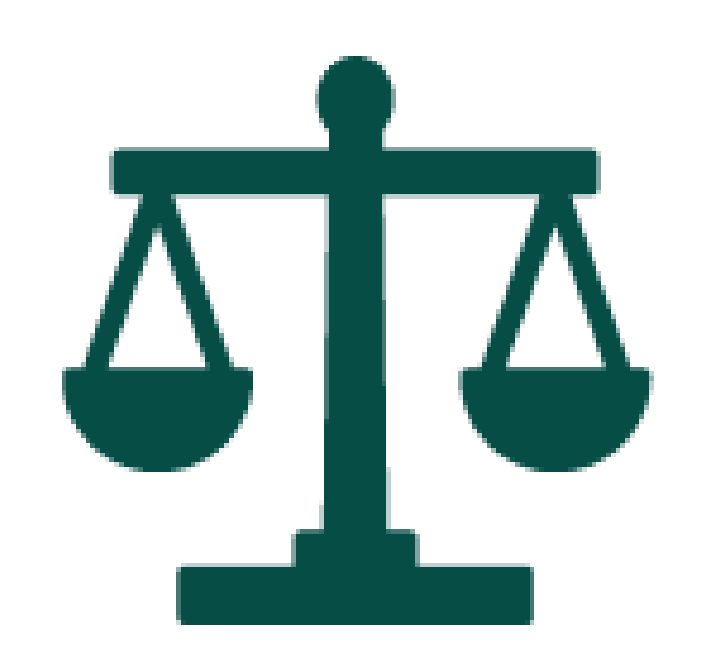

\title{
Results
}
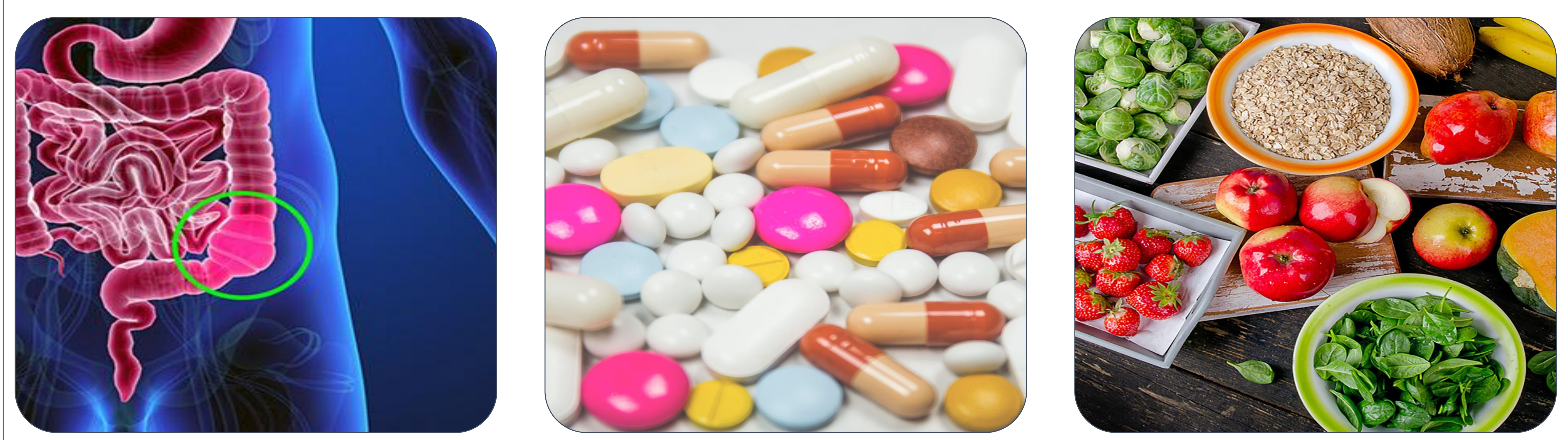

\section{Physical symptom}

Constipation was seen as simple to manage, with a focus on the symptom's physical manifestation. Assessment and management were approached from an identified the psycho-social implications for the patient.

"Constipation is often seen as a simple thing... It's pretty straight forward" Nurse objective stance. Few HCPs

Pharmacologically driven
management
Strength
pharmacological
management was evident,
with discussions of drug
choices dominating the
conversation
"We probably all have
[laxatives] we turn to on a
regular basis..." Doctor
"We are very good at the
pharmacological
interventions" Nurse

Pharmacologically driven management

pharmacological management was evident, with discussions of drug choices dominating the conversation

"We probably all have [laxatives] we turn to on a "We are very good at the interventions" Nurs

\begin{abstract}
Lifestyle modifications under-utilized

Lifestyle modifications were rarely discussed. Difficulties were reported regarding implementation in this setting

"You can't always
implement lifestyle
modifications. You can't
get people as mobile. You
can't get them to take the
volumes of fluid or make
changes to their diet, less
so than someone who is
well" Pharmacist
\end{abstract}

\section{Barriers}

Embarrassment, confusion, secondary symptom status, poor documentation, physical limitations

\section{Facilitators}

Professional status/approach of the HCP, team communication, the environment, the patient and relatives, adequate resources

"When families are there...they are very embarrassed "The fact you're a doctor or a nurse, people will then and want you to walk out of the room" Nurse open up about all sorts of things very easily" Nurse

\begin{tabular}{|l|}
\hline References \\
1 National Institute for Health and Care Excellence. Constipation [Internet]. \\
Clinical Knowledge Summaries. 2017 Jun [cited 2018 Dec 13]. Available \\
from: https://cks.nice.org.uk/constipation\#!!topicsummary \\
2. WHO. WHO Definition of Palliative Care [Internet]. World Health \\
Organization; 2017 [cited 2017 Apr 12]. Available from: \\
http://www.who.int/cancer/palliative/definition/en/
\end{tabular}

If you would like more information, please contact Deborah Muldrew: d.Muldrew@ulster.ac.uk

Poster author will be present: Poster Presentation Set 2 on 24.05.2019.

I have no potential conflict of interest to report

\section{Discussion}

- By focusing on the physical symptom, HCPs overlooked the psychological and social implications of constipation throughout the assessment and management of the patient

- Clinical guidelines on constipation management in palliative care call HCPs to incorporate nonpharmacological strategies alongside pharmacological intervention, including optimising toileting, privacy, diet and fluids, and mobility. 